\title{
PHYSIOLOGICAL CHANGES ASSOCIATED WITH UNILATERAL PULMONARY VENTILATION DURING OPERATIONS ON THE LUNG
}

\author{
Robert Bachand, Jacques Audet, Roger Meloche, and Rosario Denis
}

To FACILITATE the work of the thoracic surgeon it has become accepted procedure in certain circumstances to collapse the diseased lung being operated upon. To accomplish this, the technique most frequently used by the anaesthetist in this country calls for the insertion of a double lumen bronchial tube. This makes it possible to isolate the intact dependent lung from the diseased upper one and thus to prevent contamination of the sound lung. On the other hand, collapse of the uppermost lung causes serious functional respiratory modifications which call for special compensatory measures to avoid hypoxaemia. The purpose of this report is to stress again that optimum maintenance of oxygenation is crucial to the prevention of sustained cellular hypoxia and to show how this may be achieved.

\section{METHODS}

Eighteen patients were studied during routine operations on the lung carried out in the full lateral position. Pertinent clinical information on the patients included in this series is listed in Table $I$.

Premedication consisted of meperidine, 50 to $75 \mathrm{mg}$ and atropine sulfate $0.4 \mathrm{mg}$ administered intramuscularly one hour before the operation. After induction with thiopentone 4 to $6 \mathrm{mg} / \mathrm{kg}$ body weight, succinylcholine $2 \mathrm{mg} / \mathrm{kg}$ of body weight was given intravenously and the larynx was sprayed with 4 per cent lidocaine. After passage of the bronchial tube its position was checked by auscultation before and after posturing of the patient in the lateral position.

Anaesthesia was maintained with halothane 0.5 to 1.5 per cent vapourized in 95.5 to 98.5 per cent oxygen. Nitrous oxide may be added later, depending upon $\mathrm{Pa}_{\mathrm{O}_{2}}$ levels. Muscular relaxation was maintained by intermittent doses of D-tubocurarine. The lungs were ventilated with a volume-preset Engstrom ventilator at a frequency of 16 cycles per minutes. A tidal volume of $12 \mathrm{ml} / \mathrm{kg}$ body weight was used. Following induction, the radial artery was cannulated percutaneously with a 20-gauge teflon catheter. Evaluation of pertinent parameters was done on two occasions during the operation. The first assessment was carried out after the patient had been postured in the lateral position and the pleural cavity had been opened for more than ten minutes with both lungs ventilated and perfused. At this time three samples were collected for analysis. A sample of venous blood from the pulmonary artery was taken directly by the surgeon, one of arterial blood was drawn from the previously cannulated radial artery and a sample of mixed expired

From the Department of Anaesthesia, University of Montreal Medical School and Department of Anaesthesia, Notre-Dame Hospital, Montreal, Quebec, Canada. 
TABLE I

\begin{tabular}{|c|c|c|c|c|}
\hline Patient no. & Sex & Age & Diagnosis & Operation \\
\hline $1 \mathrm{HB}$ & $\mathrm{M}$ & 45 & Ca of R.U.L. & Lobectony \\
\hline $2 \mathrm{RB}$ & $\mathbf{F}$ & 53 & Ca of R.U.L. & Lobectomy \\
\hline $3 \mathrm{FC}$ & $\mathbf{F}$ & 47 & Ca of R.U.L. & Lobectomy \\
\hline $4 \mathrm{MC}$ & $\mathrm{F}$ & 54 & Tbc of R.U.L. & Lobectomy \\
\hline 5 RD & M & 60 & Ca of R.U.L. & Lobectomy \\
\hline $6 \mathrm{LD}$ & M & 57 & Ca of R.U.L. & Pneumonectomy \\
\hline $7 \mathrm{AD}$ & $\mathrm{M}$ & 45 & Ca of R.U.L. & Lobectomy \\
\hline $8 \mathrm{RG}$ & M & 52 & Ca of R.U.L. & Lobectomy \\
\hline $9 \mathrm{GG}$ & M & 50 & Tbc of R.U.L. & Lobectomy \\
\hline $10 \mathrm{NG}$ & $\mathrm{F}$ & 23 & Bullous Emphysema & Plication of Bullae \\
\hline $11 \mathrm{HH}$ & M & 70 & Ca of R.U.L. & Lobectomy \\
\hline $12 \mathrm{GK}$ & $\mathrm{M}$ & 41 & Ca of R.L.L. & Lobectomy \\
\hline $13 \mathrm{GL}$ & MI & 60 & Ca of Right Lung & Pneumonectomy \\
\hline $14 \mathrm{AL}$ & M & 66 & Ca of L.L.L. & Lobectomy \\
\hline $15 \mathrm{LM}$ & $\mathrm{M}$ & 59 & Ca of R.U.L. & Labectomy \\
\hline $16 \mathrm{FP}$ & $\mathrm{M}$ & 70 & Ca of L.U.L. & Lobectamy \\
\hline $17 \mathrm{I}, \mathrm{R}$ & M & 50 & Ca of R.U.L. & Lobectomy \\
\hline $18 \mathrm{MW}$ & $F$ & 58 & Ca of R.U.L. & Lobectomy \\
\hline
\end{tabular}

gases was collected during a three-minute period in a 60-litre nylon Douglas bag, according to standard procedure.

Thereafter ventilation to the upper lung was discontinued. After ten minutes of one-lung ventilation (O.L.V.) with both lungs perfused and the pleural cavity opened, a second assessment was carried out. Samples of venous blood, arterial blood and mixed expired gases were collected again. Biochemical analyses of blood and gas samples were performed using procedures which have been described in detail elsewhere. ${ }^{1}$ From these results, cardiopulmonary function was assessed by means of a computer and based on the Riley-Cournand equations.

\section{Results}

\section{Elimination of Carbon Dioxide}

During one-lung anaesthesia, the anaesthetist reduces the surface on which respiratory gas transfer takes place. Under such circumstances, should one lung be expected to perform the work of two lungs? In order to assess the efficiency of one-lung ventilation, carbon dioxide clearance, mean arterial carbon dioxide tension and the ratio of dead space to tidal volume (VD/VT) were studied while the unilateral tidal volume was maintained at the same level as that originally distributed to both lungs.

Results listed in Table II indicate that the carbon dioxide clearance, the arterial carbon dioxide tension and the ratio of dead space to tidal volume (VD/VT) change very little while the ventilation volume of the one lung is maintained at the same level as that previously distributed to both lungs. Under the same experimental conditions Kerr et al. ${ }^{2}$ noted significant falls in both mean $\mathrm{Pa}_{10 .}$ ( 33 to 30 Torr) and VD/VT ( 51 to 45 ). These findings suggest that, in one-lung anaesthesia, the normal ventilated lung is efficient enough to keep the carbon dioxide tension in the normal range provided that the ventilation volume of the one lung is maintained at the same level as that originally distributed to both lungs. To main- 
TABLE II

\begin{tabular}{lcccc}
\hline & $\begin{array}{c}\mathrm{VE} \\
\mathrm{L} / \mathrm{min} \\
\mathrm{BTPS}\end{array}$ & $\begin{array}{c}\mathrm{V}_{\mathrm{Co}_{2}} \\
\mathrm{ml} / \mathrm{min} \\
\text { STPD }\end{array}$ & $\begin{array}{c}\mathrm{PaCO}_{2} \\
\mathrm{~mm} \mathrm{Hg}\end{array}$ & $\begin{array}{c}\mathrm{VD} / \mathrm{VT} \\
(\%)\end{array}$ \\
\hline $\mathrm{TLV}$ & 73.4 & 69.8 & 41.6 & 48.5 \\
OLV & 71.5 & 67.3 & 41 & 46.5 \\
\hline
\end{tabular}

Comparison of ventilation, $\mathrm{CO}_{2}$ clearance, $\mathrm{PacO}_{2}$ and the VD/VT during two-lung ventilation (TLV) and after 10 minutes of one-lung ventilation (OLV) on 18 patients. Only the means are shown; the standard deviations were statistically not significant.

tain the ventilation volume throughout one-lung anaesthesia, a volume preset ventilator is mandatory.

\section{Oxygenation}

To evaluate the adequacy of oxygenation of the arterial blood during one-lung ventilation the factors which govern oxygenation of the arterial blood must be considered. These are the intrapulmonary right to left shunting or the proportion of the pulmonary blood flow passing through the unventilated lung and the oxygenating efficiency of the ventilated lung, which is dependent upon the intrapulmonary right to left shunt and also on the degree of unevenness of the ventilation perfusion ratio. These two factors, however, are influenced by changes in cardiac output and thus bear further discussion.

When one lung is ventilated during endobronchial anaesthesia, the efficiency of the blood oxygenating system will be reduced by blood being shunted through the unventilated lung. Some investigators have stated that, following acute collapse of the lung, blood flow through it is reduced to such an extent that arterial oxygenation is not disturbed. Kerr, et al. ${ }^{3}$ have shown that in most cases oxygenation is affected significantly during one-lung anaesthesia. They also have demonstrated that some patients show no impairment of oxygenation provided that the circulation in the diseased lung was negligible before the operation. In our study, confirmation of Kerr's results was obtained by comparing pre-operative clinical status with per-operative results.

The following case will serve as an example of unchanged oxygenation. A 70year-old male with an epithelioma of the right upper lobe and symptomatic manifestations of one year's duration underwent thoracotomy. He had a history of chronic obstructive pulmonary disease and hypertension attributed to atherosclerotic cardiovascular disease. Results are shown in Table III. Oxygenation did not change during one-lung ventilation. That means there was minimal shunting through the upper sick lung during the one-lung anaesthesia. In other words, the circulation had been negligible in that lung before the start of the operation.

A different situation exists when the ventilation of a previously well perfused lung is interrupted. Then a considerable fall in arterial oxygen tension occurs secondary to excessive intrapulmonary shunting. Our second illustrative case involved a healthy 23-year-old female with a history of two episodes of spontaneous pneumothorax attributed to bullous emphysema. Pulmonary function tests performed pre-operatively were within normal limits and the electrocardiogram was 
TABLE III

\begin{tabular}{lccccc}
\hline \hline & $\mathrm{PaCO}_{2}$ & $\mathrm{VD} / \mathrm{VT} \%$ & $\mathrm{~Pa}_{2}$ & $(\mathrm{~A}-\mathrm{a}) \mathrm{D}_{\mathrm{O}_{2}}$ & Qs/Qt \\
\hline TLV & 38 & 51 & 294 & 375 & 29 \\
OLV & 47 & 43 & 323 & 337 & 26 \\
\hline
\end{tabular}

Seventy-year-old male with C.O.P.D., carcinoma of right upper lung and hypertensive cardiac atherosclerotic disease.

TABLE, $1 \mathrm{~V}$

\begin{tabular}{lccccr}
\hline \hline & $\mathrm{Paco}_{2}$ & $\mathrm{VD} / \mathrm{VT} \%$ & $\mathrm{PaO}_{2}$ & $(\mathrm{~A}-\mathrm{a}) \mathrm{D}_{\mathrm{O}_{2}}$ & $\mathrm{Qs} / \mathrm{Qt}$ \\
\hline $\mathrm{TLV}$ & 40 & 47 & 570 & 96 & 4.2 \\
$\mathrm{OLV}$ & 40 & 45 & 190 & 476 & 23.6 \\
\hline
\end{tabular}

A 23-year-old female with normal lung parenchyma and bullous emphysema of the right upper lung.

TABLE V

\begin{tabular}{llccl}
\hline \hline & $\mathrm{PaO}_{2}$ & $(\mathrm{~A}-\mathrm{a}) \mathrm{D}_{\mathrm{O}_{2}}$ & $\mathrm{Qs} / \mathrm{Qt}$ & $\mathrm{Qt}$ \\
\hline $\mathrm{TLV}$ & 325 & 343 & 25.8 & 5.5 \\
OLV & $190.5^{*}$ & $480^{*}$ & $37.6^{*}$ & 5.4 (ns) \\
\hline
\end{tabular}

Comparison of the mean values for $\mathrm{Pa}_{0_{2}}$, alveolar-arterial oxygen gradient, right to left shunt $\left(Q_{s} / Q t\right)$, and cardiac output during TLV and $O L V$ on our eighteen patients.

normal. Laboratory results pertaining to this patient are shown in Table IV. On one-lung anaesthesia, the shunt increased considerably so that the arterial oxygen tension decreased from 570 to 190 torr. This increase in the shunt $(4.2$ to 23.6$)$ is due to considerable shunting through the unventilated lung because pulmonary circulation had been normal pre-operatively.

These two cases demonstrate that the adequacy of arterial oxygenation must be assessed at frequent intervals during one-lung anaesthesia in order to adjust the inspired oxygen concentration to the patient's requirements. Although there are exceptions to the rule, it may be stated that generally the arterial oxygen tension decreases appreciably during one-lung anaesthesia and, unless the inspired oxygen concentration is adequately adjusted, hypoxaemia may reach dangerous proportions, as shown in Table $\mathrm{V}$.

Oxygenation is grossly altered during one-lung ventilation. After ten minutes of one-lung ventilation, the partial pressure of oxygen in the arterial blood decreases from 325 torr to 190 torr. The (A-a) oxygen gradient increases to 480 torr whereas the intrapulmonary shunting increases to 37.6 per cent. All curves are statistically significant, $\mathrm{p}<0.001$. The cardiac output remains stable. The efficiency of the ventilated lung to provide adequate oxygenation depends on the extent of the intrapulmonary shunting and on the ventilation perfusion ratio.

Thoracotomy performed in the lateral position is conducive to atelectasis in the sound lower lung at normal tidal volumes $(7-8 \mathrm{ml} / \mathrm{Kg}$ of body weight $)$ and this in turn leads to hypoxaemia. In order to avoid atelectasis in the dependent lung, large tidal volumes in the vicinity of $12 \mathrm{ml} / \mathrm{Kg}$ of body weight were used, associated 
with an inspired oxygen concentration close to 100 per cent. Thus any decrease of arterial oxygen tension secondary to mismatching of gas and blood or due to atelectasis in the ventilated lung was avoided.

Attention must also be directed to the effect of change in cardiac output on the delivery of oxygen to the tissues. During one-lung anaesthesia, as the shunt fraction is often high (37.6 per cent for our patients), considerable changes in arterial oxygen tension will be produced by alterations in cardiac output. ${ }^{3}$ In the lateral position and with the thoracic cavity open, many factors may cause the cardiac output to decrease: anaesthetic agents, rapid blood loss, pre-existing hypovolaemia, the weight of the contra-lateral lung on the heart and some surgical manoeuvres all can impede venous return. When cardiac output decreases, less oxygen is available to the tissues. ${ }^{4,5}$ This tissue hypoxia has detrimental effects on organs sensitive to deprivation of oxygen such as heart and brain. The efficiency of the heart as a pump is thus decreased; so further aggravating the low cardiac output. The combination of low cardiac output, low inspired oxygen concentration, anaemia and hypovolaemia secondary to acute blood loss may cause cardiac arrhythmia and, in extreme cases, cardiac arrest during this type of operation. To avoid these complications, ${ }^{6}$ maintenance of a near-normal cardiac output must be attempted. In our patients there was no significant change in cardiac output. These desirable conditions were obtained by pre-operative correction of anaemia if haemoglobin was below 12 grams per cent; maintenance of normovolaemia by transfusions and administration of colloidal and lactated Ringer's solutions; avoidance of metabolic and respiratory acidosis; use of anaesthetic agents that do not unduly depress the myocardium such as halothane at low concentration, neuroleptanalgesia, or ketamine; avoidance of respiratory alkalosis that decreases the delivery of oxygen to vital tissues; administration of inotropic agents during the operation, if necessary, to maintain good cardiac output: in this regard isoproterenol or epinephrine were preferred to digitalis.

As mentioned previously, one-lung anaesthesia is accompanied by a fall in arterial oxygen tension and, in our study, large individual variations in the magnitude of this phenomenon were observed. One hundred per cent oxygen is administered during induction and serial arterial oxygen tension determinations are performed, mostly at the start of one-lung anaesthesia; when the $\mathrm{Pa}_{0.2}$ is over 200 torr nitrous oxide is introduced into the mixture of inhaled gases to achieve an arterial oxygen tension which stabilizes at about 100 to 120 torr. When the $\mathrm{Pa}_{0_{2}}$ is below 100 torr with 100 per cent oxygen inspired, both lungs are ventilated with oxygen ${ }^{7}$ and in the cases of pneumonectomy, the surgeon is asked to ligate or clamp the pulmonary artery of the diseased lung as soon as this can be accomplished.

\section{SUMMARY}

No important changes in the respiratory parameters were observed during onelung anaesthesia. However, this kind of thoracic intervention can be accompanied by a dramatic fall in arterial oxygen tension.

Methods to avoid tissue hypoxia have been described. In our series no complications whatever occurred in the operative and post-operative periods which could be related to the oxygenation of the patient. 


\section{RÉSUMÉ}

Durant l'anesthésie d'un seul poumon en chirurgie thoracique, il n'y a pas de modifications importantes dans les paramètres respiratoires. Cependant ce type de chirurgie thoracique non-cardiaque est accompagné par une baisse marquée dans les tensions artérielles d'oxygène. Nous avons décrit des méthodes pour éviter l'hypoxémie des tissus. Dans notre série, nous n'avons pas eu de complications durant les périodes per et postopératoires en ce qui concerne l'oxygénation du malade.

\section{ACKNOWLEDGMENTS}

We are grateful to the members of the thoracic surgery team, Doctors L.R. Lafleche, P. Telmosse and A. Joassin for permission to study patients under their care. The authors acknowledge the advice of Dr. G. Fortin in the preparation of this manuscript.

\section{REFERENCES}

1. Foëx, P., MrLoche, R., \& Prys-Roberts, C. Studies of anaesthesia in relation to hypertension. III: pulmonary gas exchange during spontaneous ventilation. Brit. J. Anaesth. 43: 644 (1971).

2. Kenn, J.H., Crampton Smtrh, A., Prys-Roberts, C., \& Meloche, R. Observations during endobronchial anaesthesia. I: Ventilation and carbon dioxide clearance. Brit. J. Anaesth. 45: 159-167 (1973).

3. Kerr, J.H. Physiological aspects of one-lıng (endobronchial) anaesthesia in thoracic surgery. International anesthesiology clinics 10:61-78 (1972).

4. Sullivai, S.F. Oxygen transport. Anesthesiology 37: 140-147 (1972).

5. Marshall, B.E. \& WYChE, N.Q. Hypoxemia during and after anaesthesia. Anesthesiology 37: 178-209 (1972).

6. Prys-Roberts, C. Myocardial function and anaesthesia. Intemational anesthesiology clinics 10: 11-25 (1972).

7. Torhan, S. \& Lundiorg, R.O. Carlens endobronchial catheter versus regular endotracheal tube during thoracic surgery. Canad. Anaesth. Soc. J. 18: 594-599 (1971). 